\title{
Possible high $U$ effect on secondary ion mass spectrometry (SIMS) of cassiterite $\mathrm{U}$-Pb dating
}

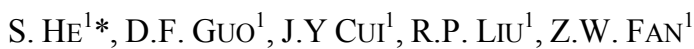

${ }^{1}$ Beijing Research Institute of Uranium Geology, Beijing 100029, China

(*correspondence:hesheng201410@163.com)

High $\mathrm{U}$ effect on secondary ion mass sectrometry for U$\mathrm{Pb}$ isotopic analysis has been found for zircon[1]. Cassiterite $\left(\mathrm{SnO}_{2}\right)$ is a common mineral in tin and sulfide deposit. Carr et al. (2017) reported SHRIMP U-Pb isotopic compositions of cassiterite for the first time and proved that crystal orientation of cassiterite does not appear to affect important analysing parameters. We preliminary evaluated high $U$ effect on CAMECA IMS1280-HR of cassiterite U-Pb dating. Our results are shown in the figure below (Fig.1,2).

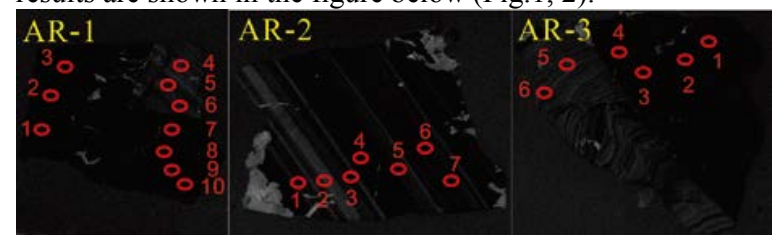

Fig 1: Cathodoluminescence images of cassiterite indicate that samples have different textures and elements concentration.

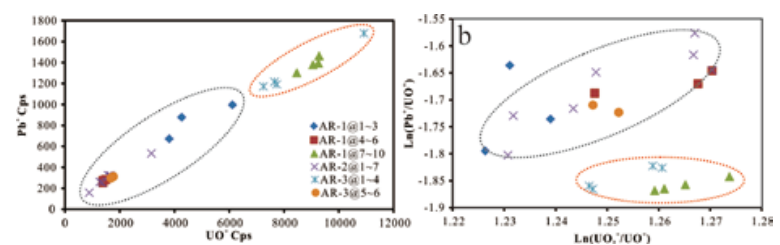

Fig 2: SIMS AR cassiterite data used in this study. a. plot of $\mathrm{UO}^{+}$versus $\mathrm{Pb}^{+}$indicates linear relationships between measured ${ }^{206} \mathrm{~Pb}^{+}$and the measured ${ }^{238} \mathrm{U}^{16} \mathrm{O}^{+}$. b. plot of $\ln \left(\mathrm{UO}_{2}^{+} / \mathrm{UO}^{+}\right)$versus $\ln \left(\mathrm{Pb}^{+} / \mathrm{UO}^{+}\right)$displays that different regions of samples have different relationship, data of samples can not define a slope with high confidence.

\section{Discussion of Results}

The relationship between $\ln \left(\mathrm{UO}_{2}^{+} / \mathrm{UO}^{+}\right)$and $\ln \left(\mathrm{Pb}^{+} / \mathrm{UO}^{+}\right)$ in high $\mathrm{U}$ concentration region of cassiterite is different from that in relatively low $U$ region, even similar slope can not be defined. It means that the U-Pb fractionation calibration may be affected by the uranium content in $\mathrm{U}-\mathrm{Pb}$ dating process.

[1]White \& Ireland (2012) CG 306-307, 78-91. [2] Carr et al. (2017) $C G$ 467, 122-133. 